\title{
Configurações da luz em Moça com brinco de pérola
}

Geraldo Carlos do Nascimento Universidade Paulista / UNIP 


\section{Resumo}

Este trabalho pretende chamar atenção, amparado basicamente num texto de Greimas e num estudo de Fontanille, para aspectos da linguagem visual do filme Moça com brinco de pérola (2004), dirigido por Peter Webber, que se quer fiel ao modo de composição da tela homônima - uma das obras-primas e, talvez, a mais poética, do pintor holandês Johannes Vermeer.

\section{Palavras-chave}

cinema, pintura, linguagem visual, luz, cromatismo

\section{Abstract}

This article, based on studies of Greimas and Fontanille, aims at calling attention to visual language aspects of Peter Webber's film Girl with a pearl earring (2004). To a certain extent, the film follows the composition style of the homonymous painting - one of Johannes Vermeer's masterpieces and perhaps the most poetic work of the Dutch painter artist.

\section{Key words}

cinema, painting, visual language, light, chromatism 
que se pretende com este trabalho é chamar a atenção para alguns aspectos da construção da linguagem imagética do filme Moça com brinco de pérola (2004), dirigido por Peter Webber, que se quer fiel, ao que tudo indica, ao modo de composição do quadro homônimo do pintor Johannes Vermeer (1632-1675).

Mais do que narrar a história, transmutada para o cinema a partir do romance de Tracy Chevalier (2004), o filme procura, pelo menos segundo a leitura que dele fazemos, reconstituir as articulações e configurações que a luz, filtrada por uma janela, ganha ao adentrar o interior do atelier do pintor - um tema recorrente do mestre de Delft, e que no referido quadro, ao ser explorado a partir de um mínimo de elementos, da escuridão para a claridade maximizadas, revela ao mesmo tempo a beleza-brilho sintetizada numa pérola e a emoção contida no semblante iluminado de uma mulher, figuras que, ao se duplicarem metaforicamente numa espécie de abismo reversível, conferem à obra um encanto poético único, que o filme, ao tentar esboçar não só o tema mas também o processo de construção do quadro, procura, a partir das coerções de sua própria atividade linguageira, insinuar.

Para evidenciar tais articulações, buscamos apoio no capítulo "A cor da obscuridade" do livro Da Imperfeição (2002), de Greimas, que nos inspirou, e em dados levantados em Sémiotique $d u$ visible (1995), de Jacques Fontanille, livro no qual o autor estuda as articulações entre os "estados da luz": intensidade da fonte, ou seja, as modulações das tensões entre obscuridade e claridade, cromatismo e matéria (forma de ocupação do espaço tornada perceptível pelà luz), para viabilizar um tratamento semiotizado da visibilidade. 


\section{Por uma teoria semiótica da luz}

A teoria semiótica da luz, proposta por Jacques Fontanille, e da qual somos aqui tributários, articula-se sobre a concepção da luz como fenômeno físico e, ao mesmo tempo, sobre a noção de luz como fenômeno psicológico, sem se confundir nem com uma nem com outra destas noções. Vincula-se, isto sim, a uma teoria semiótica geral, de inspiração greimasiana. Assim, do lado do plano da expressãa, os efeitos semióticos da luz derivariam das coerções que a regem no mundo físico e que respondem pelas primeiras articulações da substância da expressão, ou seja, informam sua manifestação discursiva; do lado do plano do conteúdo, estes mesmos efeitos semióticos derivariạm das condições da percepção luminosa, que informam a substância do conteúdo. Estes efeitos, no entanto, no campo de uma semiótica do visível, entram em ressonância com o conjunto das articulações semióticas do discurso e obedecem as condições de homogeneidade e autonomia da existência semiótica, onde a distinção entre "efeitos físicos" e "efeitos psicológicos" deixam de ser pertinentes.

\section{O mundo visível}

A luz é uma forma de energia ${ }^{1}$ que produz excitação, mais ou menoos intensa, nas terminações nervosas visuais. De acordo com Fontanille, se a luz é visível, é porque ela será configurada semioticamente, ou seja, dotada de um mínimo de articulação do conteúdo, e que a percepção que temos estará sob o controle desta configuração: deste ponto de vista, a luz pertence, seja ao espaço, à matéria, aos contrastes cromáticos, aos efeitos de superfície, etc. Assim, seja qual for o modo de acesso à configuração, imagem ou

1. A substância da luz, do ponto de vista do plano de expressão, comporta pouca informação: o mundo físico é negro e obscuro, atravessado por energias das quais as freqüências vão ao infinito. E seria em uma franja da energia, situada entre $0,4 \mu$ e $0,8 \mu$, que entra em interlocução com o sistema humano da visão, que surge, por meio desta interação, o mundo visivel. (Fontanille, 1995, p. 29) 
texto, os estados significantes da luz reenviam às articulações constantes e comuns.

A questão que se coloca a uma semiótica da luz será, então, a de determinar em que medida a configuração é dotada de um plano de conteúdo minimal, independentemente dos investimentos semânticos, figurativos ou narrativos que ela pode receber nos discursos concretos, sejam eles verbais ou não verbais, e de que natureza poderia ser este plano do conteúdo e suas articulações.

\section{Propriedades da luz}

Costuma-se atribuir à luz três propriedades: luminância, tonalidade e saturação. A estas propriedades, as teorias contemporâneas da percepção acrescentaram o que se pode denominar três pregnâncias da luz: a difusão, a intensidade da fonte e o cromatismo.

A luminância seria entendida como uma intensidade ligada à fonte, podendo ser interpretada como uma modulação gradual, repousando sobre o conflito central entre a escuridão e a claridade, de onde emergiria o visível.

A tonalidade resulta de uma reação qualitativa do alvo (objeto) iluminado; converteria qualitativamente, a partir da resistência e da reação do alvo, a ação da fonte.

A saturação é uma variação gradual da tonalidade (a proporção da mistura de branco), decorrente do conflito secundário entre cor e ausência de cor.

Considerando estes fatores, pode-se defender que a semiótica do visível tem por objeto a luz ela mesma, suas propriedades, suas interações com o entorno, e seus efeitos sobre os eventuais sujeitos que aparecem em representação. A teoria semiótica da luz pode afirmar a autonomia de seu objeto em relação à visão e em relação com o mundo físico; ou seja, a configuração semiótica não será derivada nem disto que se vê como um eventual sujeito, nem das propriedades do mundo físico, mas se apresentará como uma construção da qual as categorias constitutivas deverão permitir a 
descrição dos efeitos de sentido nascidos das interações (dêiticas, modais, passionais, etc) entre a atividade perceptiva-enunciativa de um sujeito e de um gradiente de energia.

A história das teorias da luz é marcada pelo conflito entre duas correntes; a primeira, acentua Fontanille, remonta a Aristóteles; e considera que a luz branca é homogênea e a cor seria obtida pela alteração desta homogeneidade; a outra, de origem mais imprecisà, considera que a luz é heterogênea e se decompõe em cores homogêneas. Os dois principais representantes modernos destas correntes são, respectivamente, Goethe e Newton. À primeira corrente vinculam-se os filósofos da Natureza alemães, como, Hegel Schelling, Schopenhauer e a fenomenologia; a segunda é assegurada pela física moderna e contemporânea.

Para os primeiros, a cor é uma modulação de um termo complexo (sombra + luz): De acordo com Schelling, a cor aparece nos confins da sombra, no limite onde se produz uma combinação dinâmica de luz e de obscuridade ${ }^{2}$.

Para a outra corrente, "a luz do sol é composta de raios diferentemente refrangiveis", disso segue-se que:

Todas as cores saem indiferentemente dos confins da. sombra sem alteração, e conseqüentemente as causas que originam as cores diferentes uma das outras não são pontos de diferentes confins das sombras por onde a luz seja diférentemente modificada, como os filósofos acreditavam até aquii. (Newton - Traité d'optique), (apud Fontanille, p. 28).

Do ponto de vista semiótico, apesar das profundas divergências que as opõem, estas duás correntes reconhecem os principais efeitos de sentido próprios à configuração; os goethianos seriam mais sensíveis à cor e a matéria; concebem a luz como um princípio de difusão e

2. Nos Aforismos, para a introdução da filosofia da natureza, pode se ler, na citação de Schelling feita por Fontanille: "Isto que é colorido é somente a imagem engendrada quando vista de maneira unitária isto que só em si é visível (a luz) e isto que por si é invisível (a não luz e as trevas)". 
expansão; já os newtonianos centrar-se-iam na luminância e na iluminação, e conceberiam a luz como um princípio de circulação vetorial. Tal divergência, no entanto, poderia ser considerada como uma diferença de ponto de vista sobre a mesma configuração - objetiva (abordagem física) e subjetiva (abordagem fenomenológica).

\section{Os quatro efeitos de sentido constitutivos da configuração}

Para a semiótica, as propriedades substanciais da luz (luminância, tonalidade, saturação) não serão arranjadas em categorias do plano do conteúdo, $e_{\text {; }}$ conseqüientemente, semiotizadas, senão no ato da enunciação que as constrói. $O$ instante dessa enunciação, que passa por todos os avatares do percurso epistemológico, desde a sensação elementar até a significação, é construído ao mesmo tempo que a configuração à qual se procura dar conta. No final do percurso, a enunciação deictiza e modaliza a luz e o mundo visível. $E$ isso pressupõe uma outra dimensão do mundo visível: o espaço, que poderia ser considerado o substrato que as propriedades da luz permitiriam articular, uma vez estabelecida a existência semiótica propriamente dita, e que forneceria um plano de conteúdo à energia. Assim, a configuração da luz; articulando um espaço atravessado por energias, daria nascimento a uma semiótica do visível.

A análise de numerosos discursos concretos e de diferentes teorias da luz faz aparecer quatro efeitos de sentido principiais, que constituem o esboço intuitivo da configuração: 1) os efeitos de luminância ${ }^{3}$, que localizam as concentrações de energia; 2) os

3. A luminância não se confunde com o efeito-fonte (que participa da iluminação e não pode ser pensada sem um alvo). Ela se sustenta em si mesma e pode afetar um lugar específico do campo visível ou o campo inteiro. Mas, seja qual for sua extensão, a luminância se caracteriza sempre por uma concentração de energia, que tende a se reduzir a um ponto; se a zona de luminância é um lugar inteiro, ela será organizada enquanto luminância em torno de um centro onde é máxima, volteada por bordas circulares onde tende a decrescer. A categoria subjacente a este efeito é a da intensidade em sua versão localizada. 
efeitos de iluminação $o^{4}$, que especificam na extensão os modos de circulação e de parceria fonte/alvo; 3 ) os efeitos de cromatismo $^{5}$, que se relacionam a lugares definidos e localizados, e determinam de qualquer modo os lugares; 4) os efeitos de matéri ${ }^{6}{ }_{\text {, de ocupação }}$ e de difusão.

A emergência destes efeitos da luz no espaço tensivo tem por consequiência 1) a aparição de actantes posicionais, que traduzem em termo topológicos as diferenças de potencial tensivo, e 2) a convocação de valências, que traduzem as modulações quantitativas e qualitativas da intensidade.

4. Se bem que se tenha por hábito no domínio da análise da imagem de reduzir a questão da luz à da iluminação Fontanille, esta não é, do ponto de vista semiótico, senão uma dimensão da luz, aquela que estabelece uma relação entre uma fonte e um alvo, controlada pela intensidade da fonte, e que repousa sobre as propriedades vetoriais do eśpaço; todas as noções de sombra e claridade, de raio e obstáculo, de fonte e lugar iluminado dela são decorrentes.

5. As cores não dependem da intensidade da fonte luminosa; não há mais fonte e alvo no cromatismo, mas somente lugares. Neste caso, a intensidade luminosa encontra-se de modo intrínseco ao objeto ou ao lugar: as cores quentes ou frias, saturadas ou dessaturadas podem então ser interpretadas como variações de intensidades luminosas próprias aos lugares, variações que engendram de um lado os tons e de outro, os valores (no sentido pictural do termo). Em suma, tudo o que localiza e situa a luz em um espaço heterogêneo engendra e/ou seleciona a cor. Do ponto de vista dos actantes posicionais, nos termos de Fontanille, a cor resulta da seguinte transformação: a porção de extensão que faz papel de alvo absorve certa intensidade luminosa e a converte em cor. Quer dizer que um outro actante emerge do dispositivo, pois o alvo se transforma enquanto tal, e se faz lugar para um local colorido, podendo fazer eventualmente papel de uma fonte secundária.

6. Quanto à luz-matéria convém entendê-la como uma forma de ocupação do espaço tornada perceptivel pela própria luz: é essa luz que informa a presença de poeiras, volumes, superfícies e texturas, em um espaço considerado intuitivamente como um continente ocupado por um conteúdo que revela a luz. A luzmatéria participa com o cromatismo de um princípio de localização por obstáculo, e assim efetua uma representação heterogênea do espaço; neste sentido, ela poderá ser explorada para situar os lugares no espaço do visível e para produzir efeitos de profundidade: as superposições de volume, de recobrimentos de formas materiais constituem uma outra maneira de situar os objetos e os lugares em relação a um observador. Mas ela partilha com a iluminação e as relações fonte/alvo um certo nível de homogeneidade: a luz materializada, tornada poeira, volume, superfície e linha, diferencia os lugares mas sem especificar os sítios; assim, se o cromatismo aparece como uma propriedade de cada sítio, a iluminação, como uma propriedade global e local, a luz matéria faculta a interação entre o global e o local. 


\section{$\mathrm{O}$ quadro que deu origem ao filme}

Nossa hipótese é de que o filme Peter Webber faz uma leitura do quadro Moça com brinco de pérola, de Vermeer, e a partir dela procura desvendar o modo de produção do pintor procurando reencontrar seus princípios, realçando suas técnicas e, particularmente, sua visão a respeito do tratamento da luz e o emprego do cromatismo. Não sem motivo, como veremos, a metáfora da câmera escura ganha no filme relevante papel.

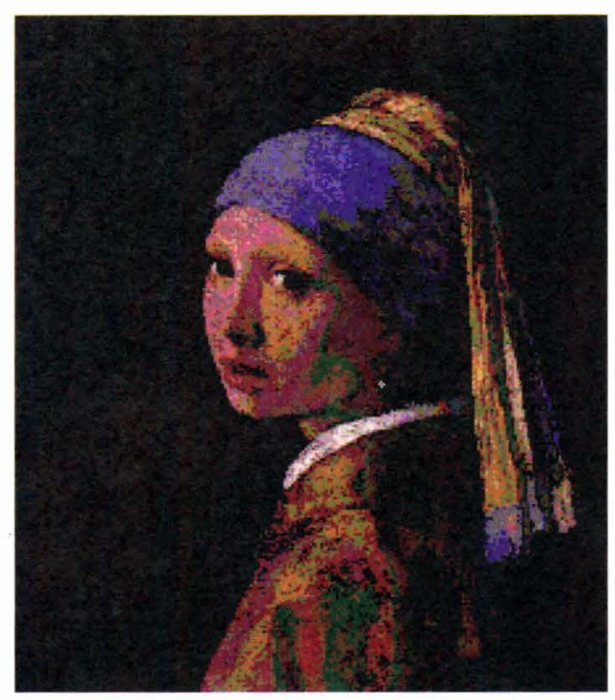

A composição do quadro se efetua a partir da articulação de luz e trevas. Seu tema único, a efígie da moça, recortada à semelhança de um plano cinematográfico americano, enfatiza seu rosto que parece emergir das trevas, que tomam conta do aposento atravessado obliquamente pela luz intensa provinda de uma janela pressuposta à sua esquerda. A moça volta o rosto ligeiramente para trás, seu olhar dirige-se para o pintor fora de campo e que se encontra, como sugere o percurso da luz, na penumbra. A incidência da luz no rosto da moça estabelece uma relação que Fontanille classifica de fonte-alvo, própria do que define como iluminação; ela é captada num ângulo que acentua 
sua intensidade, que quase alcança o limite extremo do brilho (próprio da luminância), como deixam entrever os reflexos que partem dos olhos, dos lábios e do brinco de pérola na orelha esquerda da moça retratada; pontos de luz que constituem fontes secundárias e descolorem partes de extensões cromáticas dos objetos-alvo em função da intensa luminância que neles incide. É, então, por graças de um sutil movimento de cabeça da moça para a sua esquerda que surgem espaços levemente protegidos da luz direta, de onde emergem as cores que localizam os traços que compõem o perfil da mulher e revelam características específicas dos diferentes tecidos orgânicos com que são formados olhos, nariz, boca, dentes, pérola. Cobre a cabeça da moça um turbante composto por dọis lenços: um azul, situado na parte frontal, um tanto deslocada em relação ao foco direcional da luz, e que circunda a toda a cabeça da moça, e outro amarelo-dourado, com reflexos intensos e manchas de sombreamento provocadas por pequenas dobras; este lenço cai do ponto mais alto onde forma uma espécie de laço em direção a posição mais bem iluminada. Parte do tecido azul sai por trás dele, mais à direita, e cai mais para o lado da sombra.

O dorso da moça deixa entrever um casaco amareloamarronzado, na parte iluminada; ele se torna cada vez mais escuro à medida que vai sendo encoberto pela sombra, que toma conta da parte posterior do corpo da moça que, embora visível para um dos pontos de vista do pintor, fica fora do foco da iluminação, envolto pelas trevas.

O quadro deixa evidente a proposta pictórica de Vermeer, que, como se sabe, inspirava-se nas concepções óticas de Kepler, algo diferente dos pressupostos renascentistas dos italianos que prescreviam o enquadramento do mundo de um ponto fixo externo, representado metaforicamente por uma janela, a pintura holandesa do século XVII explorava diferentes pontos de vista, situando o "olho" como que no interior do mundo:

Em Saerendam e Vermeer, o quadro manifesta um olho kepleriano móvel e ubíquo que multiplica os pontos de vista e as perspectivas, todos presentes simultaneamente 
na tela onde se cruzam olhares das personagens $e$ os vários lugares por onde passa o olho do pintor. (Chauí, 1996, p. 116)

Os quadros de Vermeer exploram com freqüência os efeitos da luz-iluminação, colocando seus modelos sob a luz que adentra $o$ interior na penumbra por uma janela, e o embate entre luz e sombra se estabelece e manifesta-se com efeitos de claro-escuro próprios da estética barroca, na sua versão holandesa. Neste quadro em especial, o pintor holandês chega a um máximo de requinte, pureza e simplicidade. As cores parecem brotar do jogo entre luz e sombra e rèvelam os objetos a partir da resistência que oferecem ao percurso luminoso. Do amarelado, quase-luz, ele passa pelo vermelho, pelo azul, chegando às sombras profundas. Ou seja, sai daluz brilho, da luminância, para a iluminação, que estabelece seu percurso extensivo atravessando a janela até encontrar objetos resistentes, que vão se revelando, como ocorre com todo o mundo visível, à medida que se instaura o cromatismo. A luz então toma conta do espaço e materializa os objetos, revelando seus contornos e formas, mas sempre limitada pelas sombras e pelas trevas.

Nesse jogo percebe-se ainda uma manipulação de ordem teórica, o vínculo do pintor com uma concepção das cores pressupõe que o cromatismo nasce exatamente deste embate entre luz e trevas. Não por acaso, as cores convocadas - amarelo, azul, vermelho - as cores que se combinam no quadro, quando somadas resultam no preto:

Compreende-se então melhor o sentido dessa abordagem gerativa do objeto: a obscuridade, concebida como uma aglomeração de corpúsculos, produz matéria negra que se deixa ver, na superfície fenomênica, como um objeto estético. Por outro lado, é sabido que se um pintor mescla amarelo, azul, vermelho, obtém cor preta. (Greimas, 1987, p. 51/52)

Tem-se, então, em Vermeer uma espécie de reversão: as cores que saem da obscuridade a ela podem voltar. Os efeitos da luz 
bordam seu caminho na escuridão, que, como revela Tanizaki no referido texto comentado por Greimas, também as podem ocultar num "bater de pálpebras" ou, quem sabe, num leve deslocamento do ponto de vista, como o quadro de Vermeer deixa entrever. Senão vejamos.

Caso a moça efetuasse um leve movimento no sentido contrário ao que realizou - em vez da direita para a esquerda, da esquerda para a direita - este movimento a situaria diretamente no foco da luminância eliminando as zonas de sombra de seu rosto; ele então brilharia; como brilha o brinco de pérola, e nenhuma cor, nenhum objeto conhecido poderia nele ser discernido. As cores e o quadro, por conseqüência, não apareceriam, como na obscuridade desapareceram as fagulhas multicoloridas que, por um instante, haviam encantado o personagem de Tanizaqui ao contemplar as trevas de um interior, como citado por Greimas. Esta conversão de rosto em brilho, faz com que entre a moça e o brinco de pérola se estabeleça uma relação metafórica em abismo: ela brilha como o brinco, a jóia rara, ao se dispor de frente para a luz.

\section{A leitura que o filme faz}

O filme de Péter Webber tem a ambição de incorporar em sua linguagem procedimentos pressupostos no quadro de Vermeer, apresentando uma solução imagética para as sugestões e hipóteses desenvolvidas no texto romanceado de Tracy Chavalier. Segue o livro de perto, mexendo pouco na ordem dos episódios e não alterando sua estrutura narrativa; efetua uma ou outra mudança apenas para melhor se adequar à linguagem imagética, quando precisa ficar mais próximo do mostrar do que do contar, para criar um efeito ao mesmo tempo visualmente mais impactante e mais proximo de uma solução cinematográfica.

Começa com a cena em que Griet - o nome que a moça recebe na história - corta legumes coloridos e com diferentes formatos e os distribui cuidadosamente numa travessa de cozinha, compondo um arranjo estético. É o primeiro traço do perfil que o filme aos 
poucos vai compondo da personagem que, por questão de tendência natural, gosto e temperamento, parece já estar destinada para o encontro crucial que viria ter com o pintor. $O$ trajeto de mudança da moça da casa paterna para a residência dos novos patrões é aproveitado para fazer tomadas áreas da cidade de Delft, mostrar o casario; as ruas, os canais, cenas do cotidiano, com animais, galinhas e patos, circulando entre transeuntes, compondo uma reconstituição de época convincente, uma vez que já conhecida pela documentação efetuada por uma vasta tradição pictórica holandesa. Tal procedimento é reiterado sempre que Griet sai ás ruas para ir às compras na praça do mercado - e se pode assistir a passagem do tempo pela chegada do inverno, que muda a configuração da cidade. $\mathrm{Na}$ fotografia do cenário, o tratamento da luz tenta ser cuidadoso e o filme procura sugerir a atmosfera encontrada em outros quadros de Vermeer e mesmo de outros pintores holandeses. Maš são nas cenas de interiores, particullarmente as noturnas, que tal verossimilhança procura encontrar maior eficácia - propicia o jogo claro-escuro de modo mais acentuado è remete o procedimento à estética barroca.

As ceñas noturnas são ilũminadas pela-luz àvermelhadas de tochas, que produzem úm círculo de luminância limitado, e isso confere à relação luz-trevas um dinamismo estético de que o filme soube tirar partido. Em cenas mais abertas, como a do banquete em que se comemóra o batizado de Francisco, o filho então recém-nascido de Vermeer,' a iluminação à vela, provinda de castiçais dispostos nos quatro cantos da sala de jantar, provoca o efeito de uma luz mais clara e amarelada, capaz de iluminar toda a grande mesa com os convivas. A cena, uma subjetiva de Greit, feita a partir da escada que dá acesso ao sótão e que tira partido, ainda, da transparência de uma vidraça, compõem uma imagem que lembra uma cena pictural. Fixar algumas cenas por alguns instantes e aproximá-las de telas picturais é uma solução reiterada pelo filme, que nunca deixa o espectador esquecer de que seu tema básico é a pintura, mas faz as devidas aproximações com as imagens cinematográficas e, sempre que possível, chama a atenção para o tratamento da luz.

O efeito dos reflexos provocado pelo brilho das tochas que iluminam os barcos nos canais, e os espelhos que as águas formam, 
aqui e ali, duplicando as imagens, contribuem para criar uma atmosfera, que o filme procura associar ao universo pictural de Vermeer. A pouca informação bibliográfica sobre a vida do pintor parece ser compensada ou ilustrada - desde as soluções encontradas pelo romance -, por uma aura de mistério e silêncios alusivos que cercam sua figura. O filme procura traduzir isso, por olhares furtivos, sempre à espreita de algo, por travellings vagarosos e hesitantes ao longo de corredores, e com a câmera que estanca frente a uma porta entreaberta, situação em que o claro-escuro se materializa em dois blocos: o de fora com a luz estourada e o interior na penumbra:

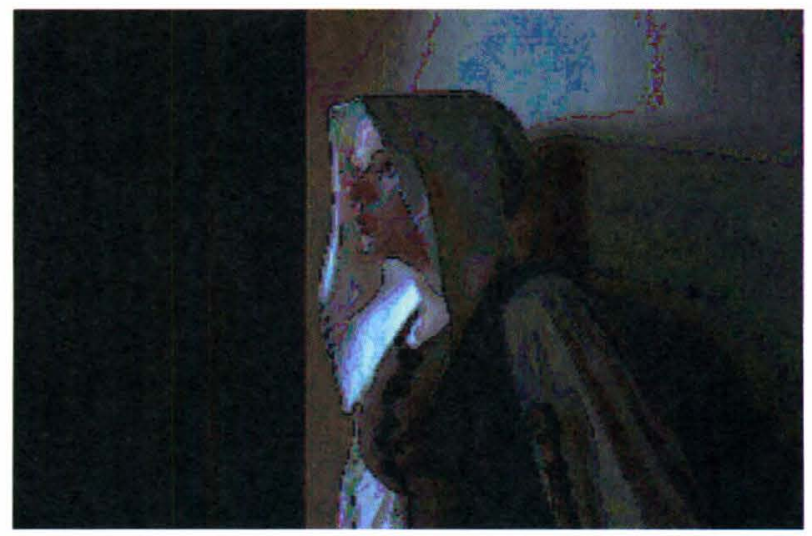

Mas são com as idealizações sobre a figura de Griet personagem inteiramente fictício - que o filme paga seu maior preço em favor de uma narrativa feita para contentar o público: além de musa inspiradora, a moça é representada com sensibilidade suficiente para fazer sugestões e mesmo "ensinar" procedimentos ao mestre pintor.

Não obstante certo exagero e alguns deslizes, o filme apresenta soluções engenhosas na tematização de certas concepções e técnicas adotadas por Vermeer. Neste sentido, o episódio que trata do emprego da câmera escura é exemplar.

A narrativa fílmica neste ponto afasta-se da do romance, comprometida com o modo de narrar verbal, para encontrar uma 

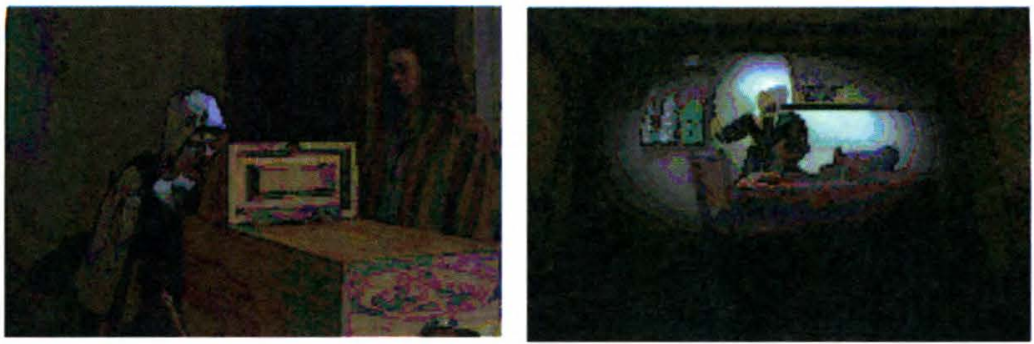

solução cinematográfica, fundada no mostrar. Assim, em vez de Griet ter informações sobre a câmera escura pela narrativa de uma criada, como acontece no livro, depara-se diretamente com ela no atelier e é convidada pelo pintor a examiná-la. Seu espanto, que não tem a mesma força no livro, motiva a explicação que o pintor faz do funcionamento da "caixa" e vincula as imagens, picturais e cinematográficas, a um mesmo processo que tem como raiz um quadro de luz que surge das trevas.

O filme encontra ainda uma solução cinematográfica para mostrar o brinco de pérolas de modo a enfatizar o relevante papel temático e actancial que a jóia teve na narrativa. Na versão cinematográfica, destacada em plongée, Griet recebe o brinco como presente (ou pagamento?) num tempo indefinido, diferentemente do que acontece na narrativa romanesca: a jóia chega cuidadoso embrulho, acondicionada entre lenços amarelo e azul, as cores mais próximas, respectivamente, da luz e das trevas. Na imagem em destaque, também uma subjetiva de Griet, evidenciam-se diferentes efeitos da luz:

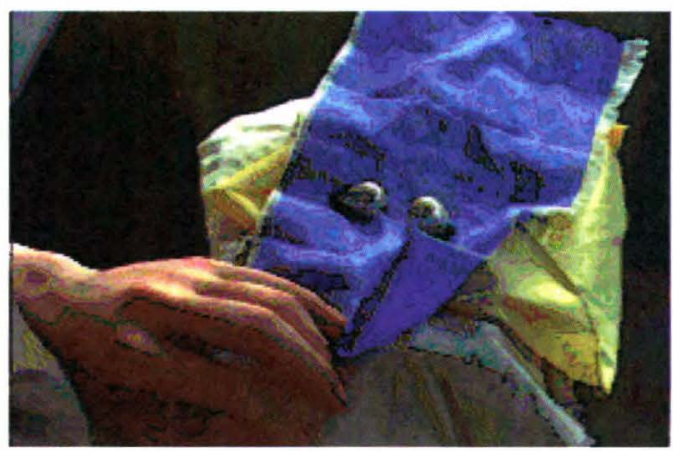




\section{Bibliografia}

CHAUÍ, M. 1996. "Imanência e Luz: Espinosa, Vermeer e Rembrandt", in Discurso N 26 (ISSN 0103-328x), São Paulo.

CHEVALIER, T. 2004. Moça com brinco de pérolà (trad: Beatriz Horta). Bertrand Brasil.

FONTANILLE; J. 1995. Sémiotique du visible - Dés mondes de lumière. Presses Universitaire de France: Paris.

GOETHE, J. W. 1993. Doutrina das cores (trad. Marco Giannotti). Nova Alexandria: São Paulo.

GREIMAS, A. J. 2002. Da Imperfeição (trad. Ana Cláudia de Oliveira). Hacker: São Paulo.

SCHOPENHAUER, A. 2005. Sobre a visão e as cores (trad. Erlon José Paschoal). Nova Alexandria, São Paulo. 